\title{
LETTERS
}

\section{Vestibular neuritis}

I would like to draw attention to an unusual sequela of vestibular neuronitis that is little known, difficult for patients to communicate, may be present in a patient whose dizziness seems to have completely recovered and may present to different specialists, including nonphysicians such as optometrists. As a 77-yearold retired general practitioner who had acute vestibular neuritis in 1980, with permanent dizziness and balance disturbance as a consequence, the CMAJ article and video demonstrations by Johns and Quinn ${ }^{1}$ were of great interest to me.

My assessments by ear, nose and throat and neurology specialists suggested the above diagnosis with a putative viral origin. Subsequently, I would have days where dizziness and balance were extra problematic and I needed the use of a cane.

Then, 10 years ago, after a day of extremely severe dizziness accompanied by visual disturbance that resolved in 24 hours, I gradually realized that a residual visual problem was present. It took a month for me to be able to work out and describe the symptom: I had lost my steady cam. This was the best I could do to put into words that the horizon was no longer stable on walking but would move up and down slightly, the phenomenon known as oscillopsia. None of my general practice colleagues were aware of this entity, and I suspect that our patients would have much difficulty getting the message across to us if this disorder were to develop.
Of added interest is that my female maternal cousin of similar age also had acute vestibular neuritis a few years ago and subsequently developed oscillopsia (this word was not used by any of her physicians). It seems odd that an entity said to be as rare as hens' teeth should occur in a close relative unless there is some genetic predisposition.

\section{Anthony J. Walter MB BCh}

Retired physician, Surrey, BC

Cite as: CMAJ 2020 June 22;192:E686. doi: $10.1503 / \mathrm{cmaj} .75014$

\section{Reference}

1. Johns P, Quinn J. Clinical diagnosis of benign paroxysmal positional vertigo and vestibular neuritis. CMAJ 2020;192:E182-6.

Competing interests: None declared. 